\title{
Effect of Soursop Leaf And Royal Jelly on Brain Neuronal Edema And Apoptosis in Rat Cerebral Contusion Model Mediated by Bdnf/Il-1 $\beta$ Ratio
}

\author{
Arif Kusumo Rahardjo*, Moch Istiadjid Eddy Santoso** \\ *) Department Of General Surgery, Faculty Of Medicine, Brawijaya University Malang, Dr. Saiful Anwar \\ Malang General Hospital \\ **) Professor Of Neurosurgery Department, Faculty Of Medicine, Brawijaya University Malang, Dr. Saiful \\ Anwar Malang General Hospital
}

\begin{abstract}
Brain injury causes disability and death. Soursop leaf extract has been widely studied as antiinflammatory and anti oxidant in non-trauma cases. The anti-inflammatory and neurotrophic effects of Royal Jelly has also been studied. The role of soursop leaf extract and Royal Jelly on cerebral contusion need to be studied.

The aim of this study is to analyze the effect of Soursop leaf extract and Royal Jelly in cerebral contusion rat model to cerebral edema and apoptosis mediated by BDNF/IL-1B ratio.

Rat is grouped into 5 groups, with 5 rats as the member. Cerebral contusion model made by applying 1,6 Joule of energy. Control group $(K)$ didn't receive Soursop leaf neither Royal Jelly. P1 Group is given $100 \mathrm{mg} / \mathrm{kg}$ Soursop leaf extract, P2 Group is given $200 \mathrm{mg} / \mathrm{kg}$ Soursop leaf extract, P3 Group is given $400 \mathrm{mg} / \mathrm{kg}$ Soursop leaf extract, P4 Group is given $100 \mathrm{mg} / \mathrm{kg}$ Royal Jelly for 7 days. Cells underwent edema dan apoptosis were counted (TUNEL), BDNF and IL-1 $\beta$ were measured (ELISA).

Soursop leaf extract decreased apoptosis ( $p$-value $<0,05)$, decreased IL-1 $\beta$ and increased BDNF ( $p$-value $<0,05)$. Royal Jelly decreased cerebral edema and apoptosis ( $p$-value $<0,05$ ), decreased IL-1 $\beta$ and increased BDNF ( $p$ value $<0,05$. The increased BDNF/IL-1 $\beta$ ratio caused decreased cells underwent cerebral edema and apoptosis (p-value $<0,05)$.

Both administration of Soursop leaf extract and Royal Jelly significantly decrease cerebral neuronal edema and apoptosis, decrease IL-1 $\beta$ and increase BDNF. The decrease of edema and apoptosis are mediated by increment of BDNF/IL-1 $\beta$ ratio.

Keywords: cerebral contusion, soursop leaf extract, royal jelly.
\end{abstract}

\section{Introduction}

Brain injury resulted in nearly half of the deaths due to trauma. Cerebral edema that occurs after brain injury is the leading cause of disability and death of brain injury patients. Cerebral edema treatment strategies that exist today as diverse as osmotic fluids, hyperventilation, sedation, neuromuscular relaxant, hypothermic, and surgical intervention [1].

Brain injury will cause the body's response is to recover himself. Recovery depends on the conditions of neurotransmitter / ionic and presence of neurotrophic (or what is known as a growth factor). One neurotrophic well known is the brain-derived neurotrophic factor (BDNF), which is secreted when there is brain injury. Some research indicates BDNF fix the motor neurobehavioral and cognitive function [2]. BDNF is a growth factor expression was more available in the brain compared to the peripheral nerves.

The changes in brain injury involves various mediators of the inflammatory response. Today a key mediator recognized is Interleukin-1 $\beta$ (IL-1 $\beta$ ). Decrease the amount of IL-1 $\beta$ is shown to improve the condition of the brain at the cellular and behavioral conditions brain injury [3].

Herbal therapy is now widely used in modern medicine. However the effectiveness of herbal therapies have been noted by a number of studies [4]. Botanical Garden of the World recorded more than 2200 species of plants around the world have the potential to be used as drugs. The growth of herbal based industries reach 7 $15 \%$ per year. Analysis of the World Health Organization, $80 \%$ of world population uses a variety of plantbased products [5]. One type of herbal medicinal plants are considered useful is Annona muricata (soursop), this plant contains flavonoids that are believed as a source of antioxidants and anti-inflammatory that could be expected to reduce the edema in the brain cells [6,7]. There are various kinds of research that has been conducted on the effects of antioxidants soursop leaves on the condition diabetes mellitus [8]. However, research on the effects of soursop leaf brain injury still has not been done.

Royal Jelly is secreted by glands hypopharynx belongs to the worker bees, to feed the young larvae and adult queen bee. Royal Jelly has antioxidant effects, neurotrophic, anti-inflammatory and immunomodulatory 
[4].Researchers questioned whether Annona muricata Soursop Leaf Extract and Royal Jelly can serve as an effective anti-inflammatory to reduce cell death and apoptosis in brain injury, through the mediation of IL-1 $\beta$ and BDNF?

\subsection{Aim}

\section{Aim And Objectives}

2.1.1 To analyze the effect of Annona muricata Soursop Leaf Extract and Royal Jelly to cerebral edema and apoptosis of brain injury, through the mediation of IL-1 $\beta$ and BDNF.

\subsection{Objectives}

2.2.1 Analyze and explain the effect of Soursop Leaf Extract and Royal Jelly in rats brain injury to the reduced levels of Interleukin-1 $\beta$.

2.2.2 Analyze and explain the effect of Soursop Leaf Extract and Royal Jelly in rats brain injury to the increase in BDNF.

2.2.3 Analyze and explain the effect of Soursop Leaf Extract and Royal Jelly in rats brain injury to the decline of cerebral edema.

2.2.4 Analyze and explain the effect of Soursop Leaf Extract and Royal Jelly in rats brain injury to a decrease in the number of apoptotic neurons.

2.2.5 Analyze and explain the effect of Soursop Leaf Extract and Royal Jelly in rats brain injury to the reduction of cerebral edema and apoptosis of neurons through the agency Ratio BDNF / IL-1 $\beta$.

\subsection{Subject of research}

\section{Materials And Method}

This research uses experimental animals as research subjects. Kind of animal was Rattus norvegicus Wistar strain, aged 12-14 weeks with a mean weight of 250-300 grams. Male sex, healthy condition of the experimental animals without any defects, active movement. Obtained from the Laboratory of Physiology of the Faculty of Medicine, University of Brawijaya. From the point of raising placed in a cage to the site of the study. Male sex been so pathophysiological process after a brain injury can be observed more clearly without the influence of the hormone progesterone.

\subsection{The inclusion and exclusion criteria}

\subsubsection{Criteria for inclusion}

- Healthy (active movement)

- Weight 250-300 g

- Males

- Age 12-14 weeks

\subsubsection{Exclusion criteria}

- Mice that were sick, disabled

- Mice that died during the study

\subsection{Materials}

1. Soursop Leaf Extract, taken from Materia Medica Government Office for Herbs Research.

2. Royal Jelly, acquired from Faculty of Animal Husbandry Brawijaya University Malang.

3. Material for examination of apoptosis: the rat brain tissue, Apoptech (Enzyme-Proteinase K, Apoptag, DAB liquid), apoptosis kit manufactured by Immunochemistry Inc.

5. Material examination IL-1 $\beta$ : rat brain tissue, Complete ELISA Kit, pink-ONE, Rat IL-1 $\beta$ (Komabiotech Inc.)

\subsection{Study design}

The research design was used to test hypotheses: experimental studies, randomized controlled trials (randomized controlled trial), posttest only design, single blinded. Researchers do not know where the rats given Soursop Leaf Extract and Royal Jelly.

\subsection{Treatment of subjects}

3.5.1 Treatment

\subsubsection{Preparation of brain injury models}

Each animal anesthetized with ketamine $100 \mathrm{mg} / \mathrm{kg}$ intramuscularly [9]. Then made observations on the success of anesthesia. This success has seen the loss of reflex reaction to painful stimuli to the skin of the 
belly, beard hair, and between the toes. After anesthesia successful, dropped a load of $0.2 \mathrm{~kg}$ pass through a cylindrical tube from a height of $0.8 \mathrm{~m}$ (1.6 Joules of energy) on the head of the experimental animals are put on fixation devices. Conflicts aimed at point $9 \mathrm{~mm}$ anterior to the coronary suture. This action will result in diffuse brain injury in rats [10].

\subsubsection{Administration of Soursop Leaf Extract}

After the treatment of brain injury action, the patient returned to the cage. Four hours later awarded Leaf Extract oral administration using a sonde in accordance with the division of the group, each within 5 minutes. Animals are maintained. Award Leaf Extract Soursop then repeated every 24 hours for 7 days in a row. Inside the cage, the animals try to get food, water and air freely.

a. P1 group. Animals in this group is given Soursop Leaf extract at a dose of $100 \mathrm{mg} / \mathrm{kg}$.

b. P2 group. Animals in this group Soursop Leaf Extract is given at a dose of $200 \mathrm{mg} / \mathrm{kg}$.

c. P3 group. Animals in this group Soursop Leaf Extract is given at a dose of $400 \mathrm{mg} / \mathrm{kg}$.

\subsubsection{Administration of Royal Jelly}

After the treatment of brain injury action, the patient returned to the cage. Four hours later awarded the $\mathrm{RJ}$ administration orally at a dose of $100 \mathrm{mg} / \mathrm{kg}$, respectively within 5 minutes. Animals are maintained. Award RJ then repeated every 24 hours for 7 days in a row. Inside the cage, the animals try to get food, water and air freely.

Giving treatment at four hours post-trauma based on the pathology of cerebral edema and brain circulation disorders ranging from the first hour and last until the 7th day [11]. Neuroendocrine changes ranging from 30 minutes post-trauma [12]. Peak increase of neurotrophin BDNF post-traumatic happened to the third hour [13] and last up to 72 hours post-injury. So that in the fourth hour of physiological body has to secrete BDNF fullest.

\subsection{Cerebral edema}

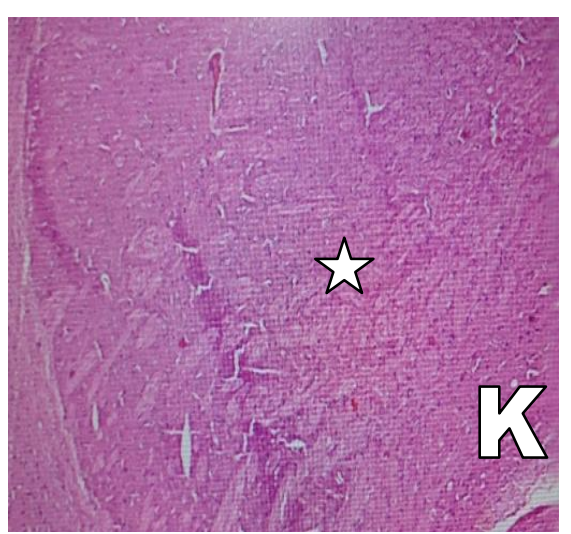

\section{Results}
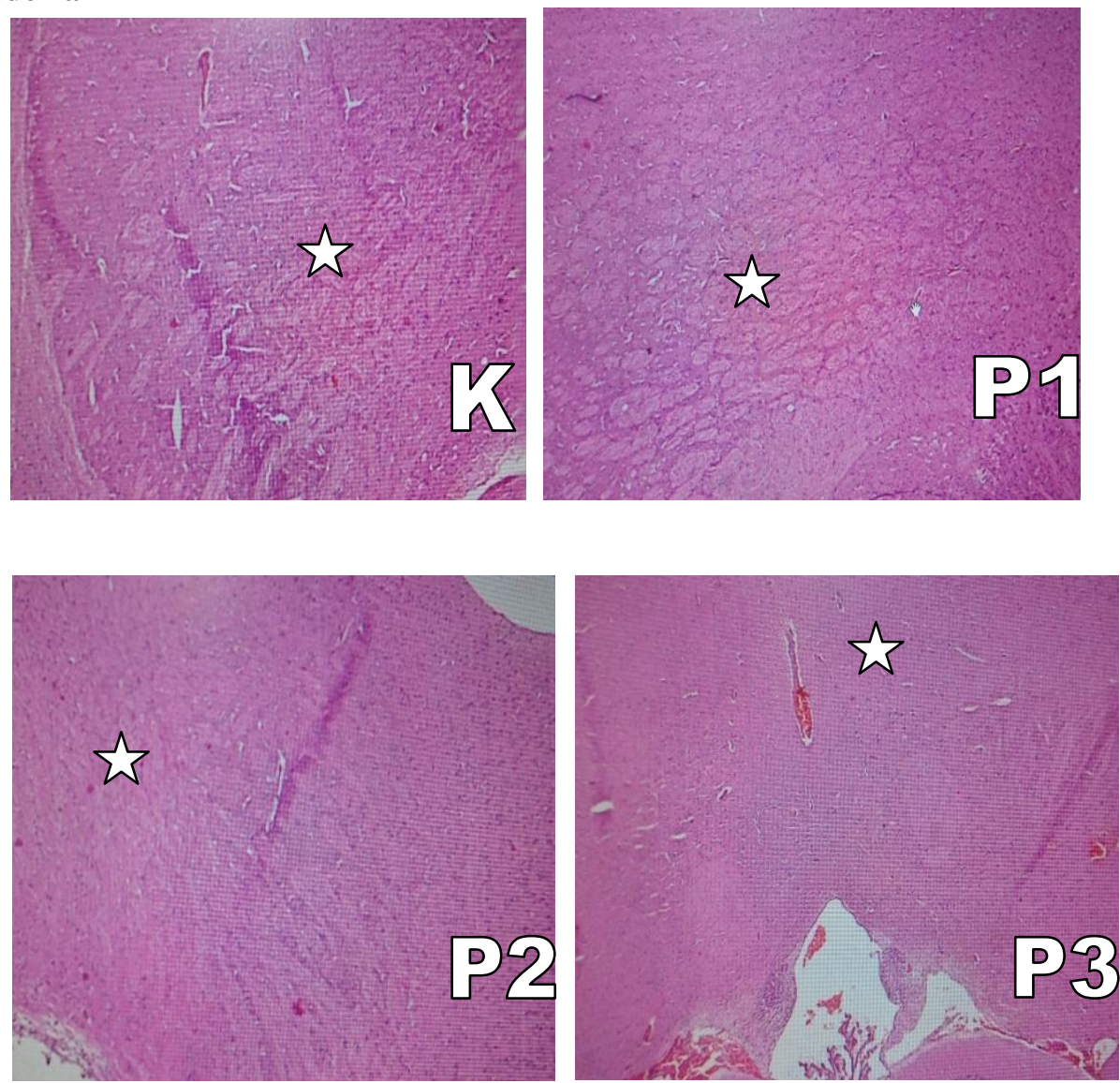


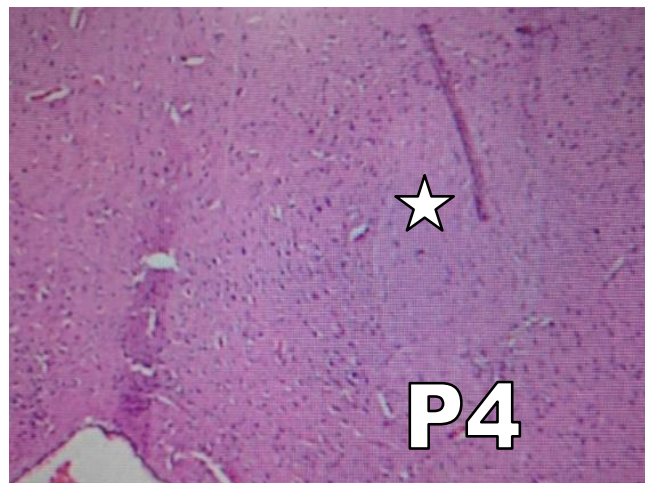

Figure 1 Cerebral edema after brain injury manufacture and delivery of treatment.

Description: Histological examination with Hematoxylin-eosin staining. The area of edema was measured using a measuring device on the computer after scanning slides. Area edema appear as pale colored areas and interstitial inflammation (star).

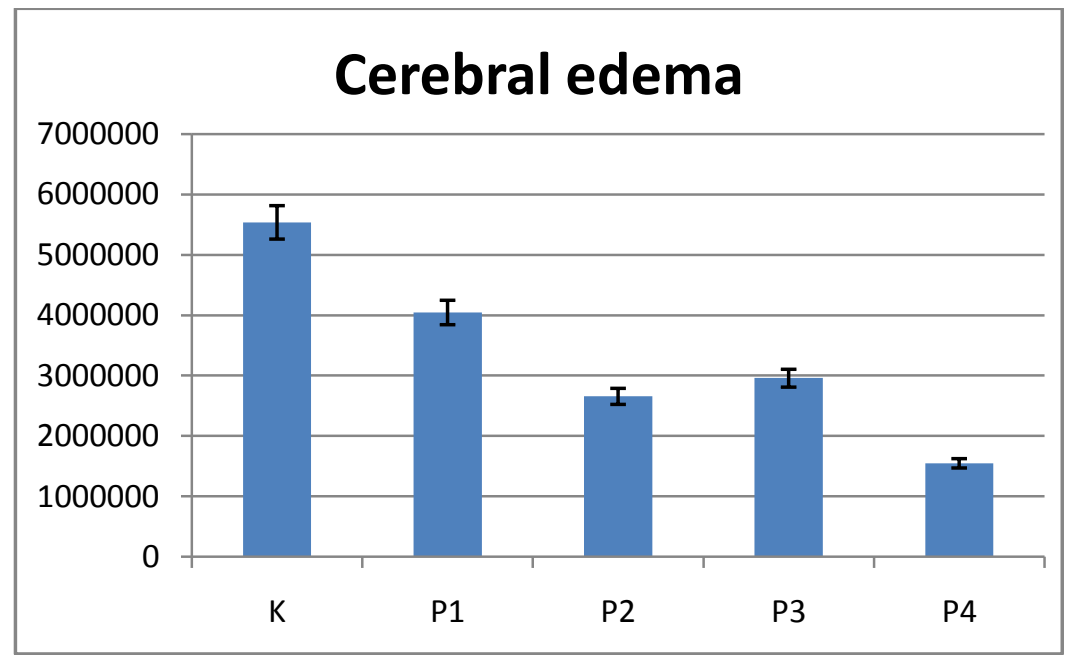

Figure 2 Cerebral edema

Description: The graph of the average area of cerebral edema after each treatment group

The highest mean of cerebral edema obtained with the control group (5,538,324.0360), and the lowest obtained in treatment P4 $(1,549,128.3080 ; \mathrm{p}<0.005)$.

\subsection{Apoptosis}

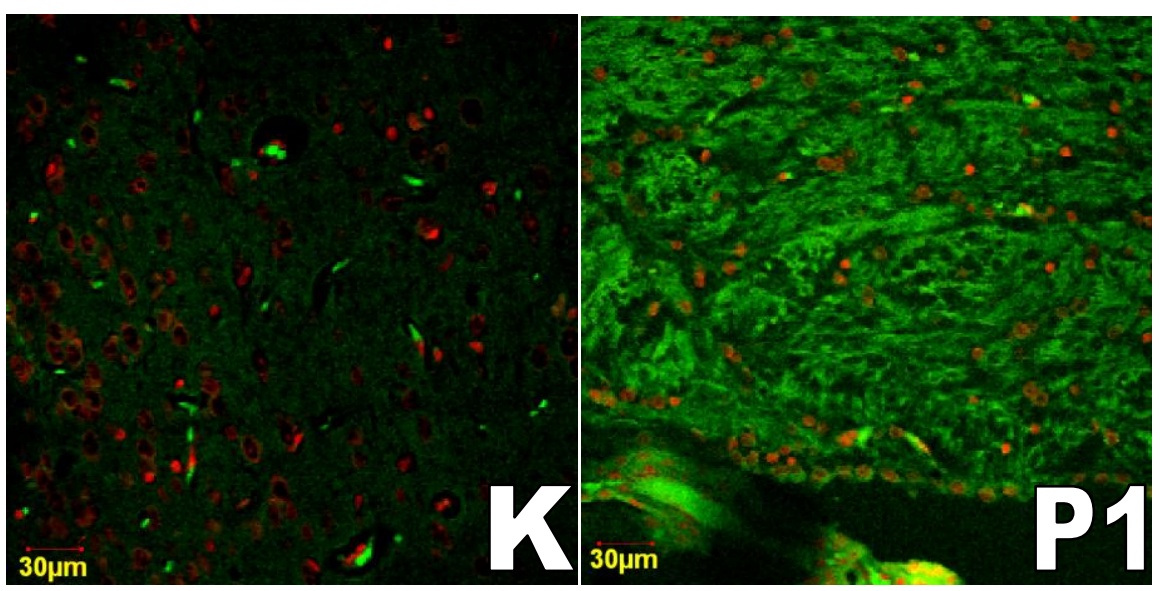



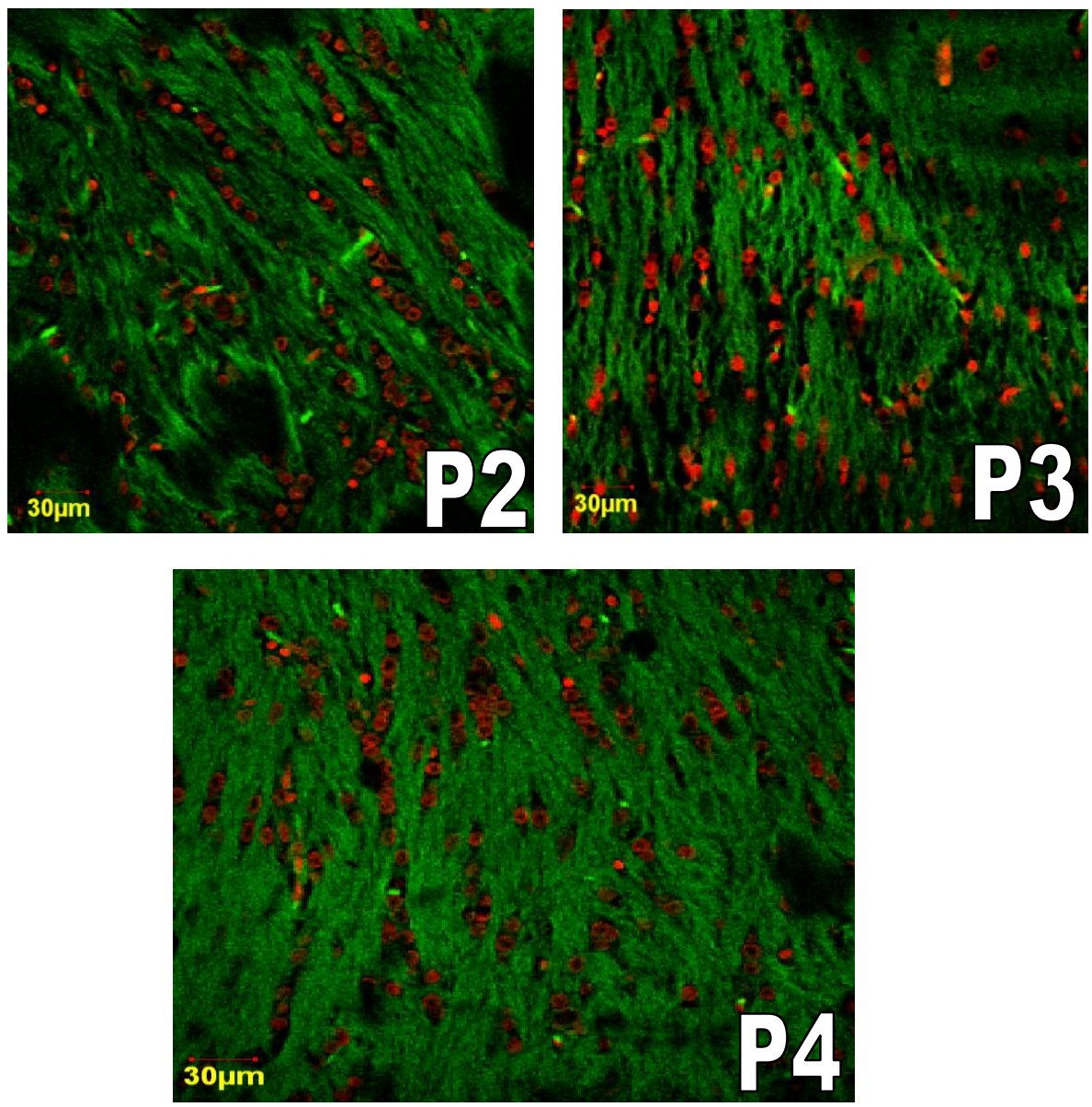

Figure 3. Microscopic neuronal apoptosis 400x magnification.

Description: Cells undergoing apoptosis has a characteristic morphological shrinkage. Nuclei appear round, condensed, fragmented.

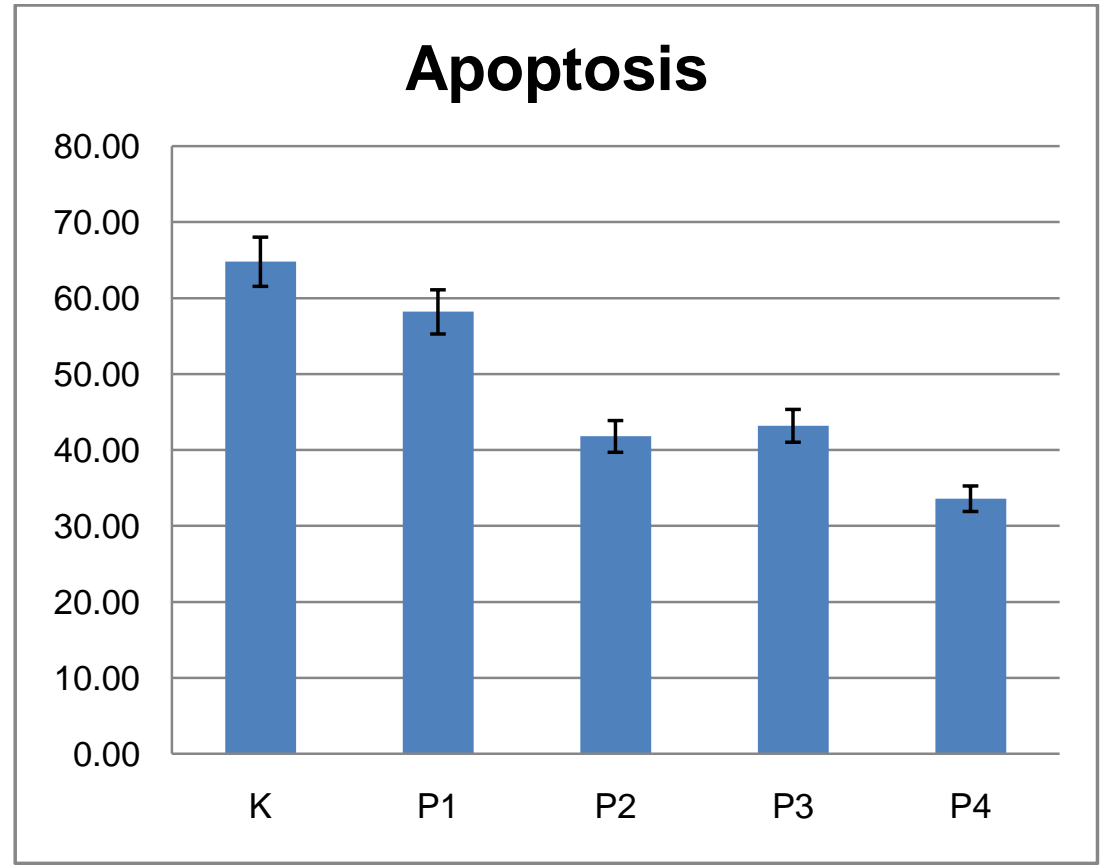

Figure 4. Apoptosis

Description: Mean of the number of apoptotic neurons per treatment group 
The highest apoptosis obtained in the control group (64.800), and the lowest obtained at treatment P4 (33.600; $\mathrm{p}<0.005)$.

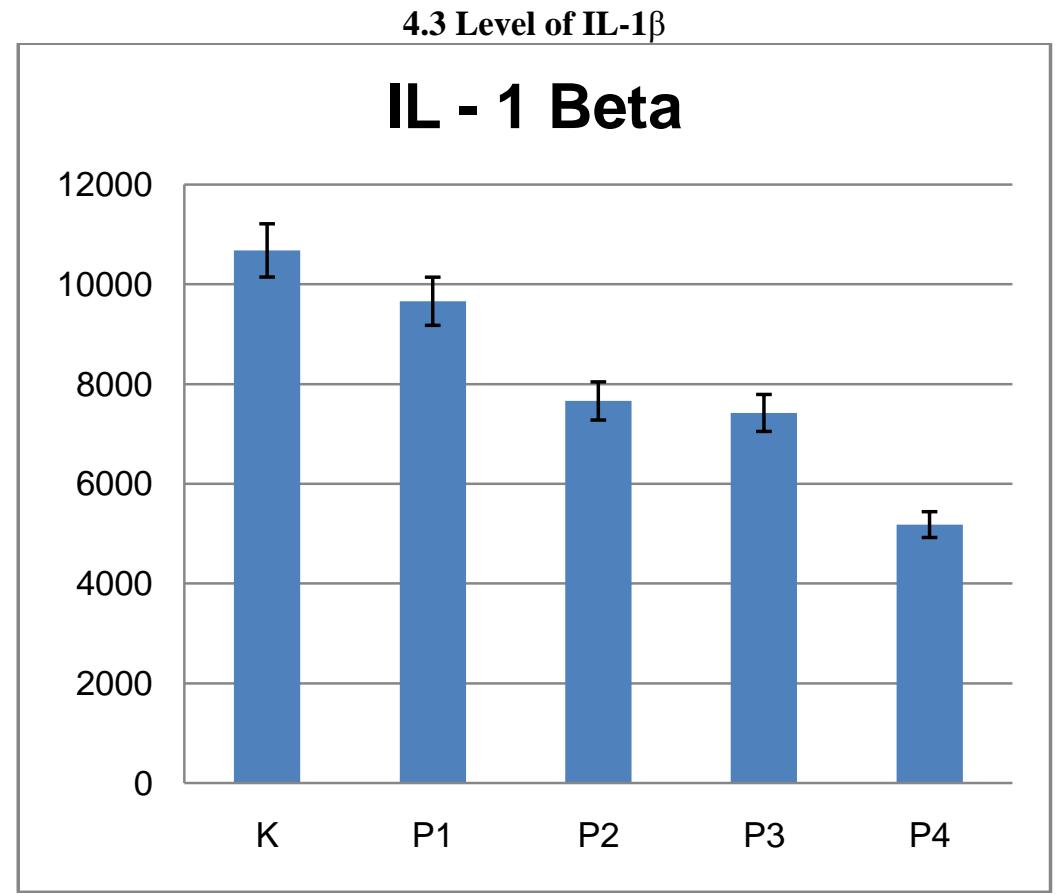

Figure 5. The level of IL-1 $\beta$

Description: The mean of the levels of IL-1 $\beta$ each treatment group

The highest level of IL-1 $\beta$ were obtained in control group (10680), and the lowest obtained in group P4 (5180; $\mathrm{p}<0.005)$

\subsection{Level of BDNF}

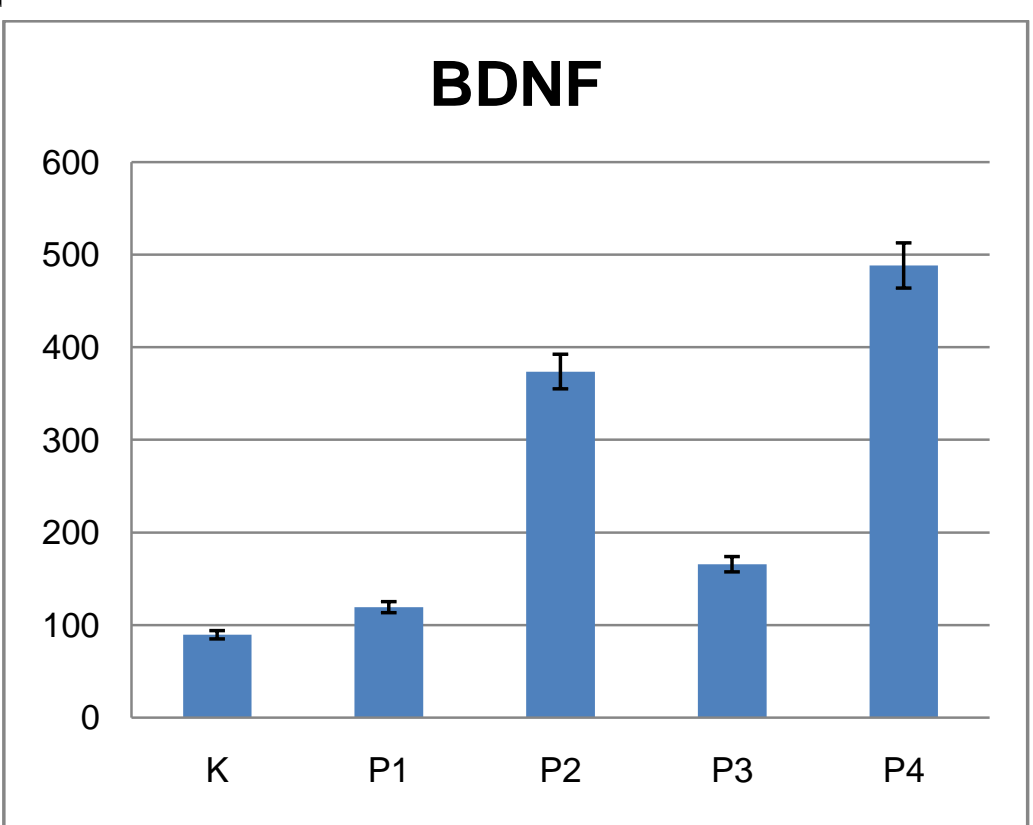

Figure 6. Level of BDNF

Description: Mean levels of BDNF of each treatment group

The highest mean obtained at treatment P4 $(488,400 ; \mathrm{p}<0.005)$, and the lowest obtained in the control $(89,400)$. 


\subsection{Effect of Ratio (BDNF/IL-1 beta) against Apoptosis}

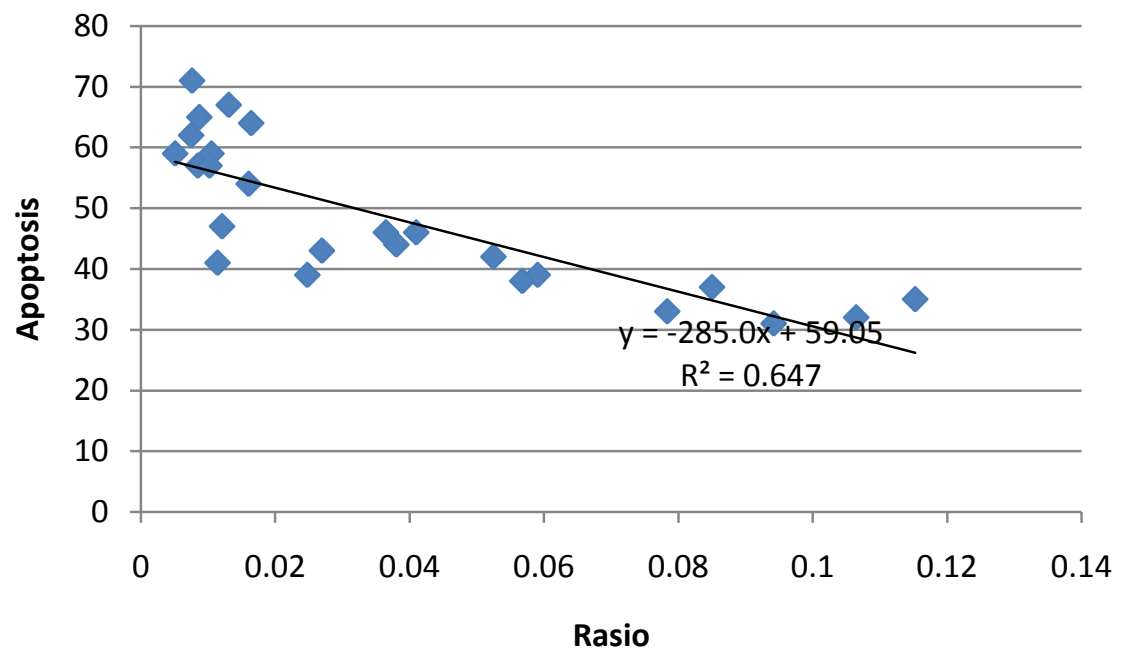

Figure 7. Curve relationship between the ratio of apoptosis

Description: Increasing the ratio will be followed by a decrease in apoptosis Ratio (BDNF / IL-1 beta) significantly affects the number variable apoptosis $(\mathrm{p}<0.005)$.

4.6 Effect of Ratio (BDNF / IL-1 beta) against Cerebral edema

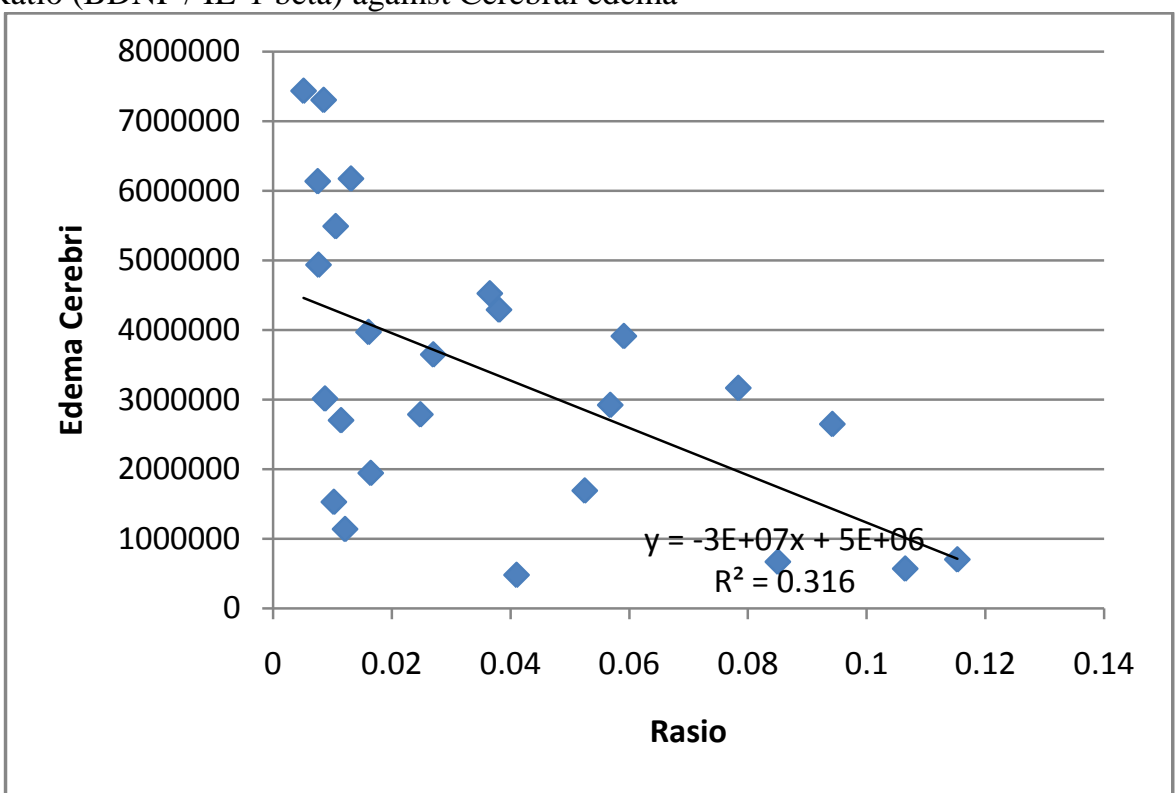

Figure 8. Curve relationship between the ratio with cerebral edema

Description: Increasing the ratio will be followed by a decrease in cerebral edema

Ratio (BDNF / IL-1 beta) significantly affects the number variable cerebral edema $(\mathrm{p}<0.005)$.

\section{Discussion}

In severe traumatic brain injury occurs to any event that is very complex. Damage caused by a primary brain injury will cause interference at the level of atoms and molecules that contribute to the function and metabolism of cells. At the level of atoms and molecules will be a series of disruption of homeostasis some ions such as $\mathrm{Ca} 2+$ ions, the formation of excessive free radicals, the formation of molecules that are toxic so that at the cellular level will be interference with cellular integrity, cell swelling, necrosis and even apoptosis. If this process continues, the brain as an organ would be disrupted so that the nervous system will be malfunctioning. With the onset of nerve dysfunction patient can fall into various degrees of impaired consciousness [14].

Neuron membrane fatty acids are susceptible to oxidative stress, because the brain receives $20 \%$ of cardiac output. Therefore, to maintain the integrity of neurons from oxidative stress should be reduced such as 
by anti-oxidants. Neuronal damage will increase the expression of BDNF synthesis, so that BDNF increases. The increase in BDNF will help the growth of neurons, defense, repair of neurons and synaptic plasticity and anti-apoptosis $[15,16]$.

Soursop leaves have chemical constituents saponins, flavonoids, tannins, acids kafeat (Soemarji, 2002). Phytosterols, Ca oxalate, alkaloids mirisine also reportedly contained in the leaves of the soursop (Iswari, 2002). Obtained from the leaves contain flavonoids-like [4,6,17]. Flavonoids in various studies showed a potent antioxidant to inhibit the oxidation of arachidonic acid [18].

Adewole et al [8] say that Soursop Leaf Extract doses of $25-100 \mathrm{mg} / \mathrm{kg}$ intraperitoneally is safe in rats. After all relatively high doses (> $200 \mathrm{mg} / \mathrm{kg}$ ) intraperitoneally cause toxic or lethal in mice. In the study also said that a single dose of Annona muricata extract significantly reduced blood glucose levels and increase serum insulin in rat models of diabetes. In mice given streptocozin (STZ) which induces oxidative stress in the liver tissue indicate that extracts of the leaves of Annona muricata have antioxidant effects that inhibit oxidative damage caused STZ known from decreasing levels of malondialdehyde (MDA) [8]. Research conducted by de Sousa et al. [19] indicates that Graviola Leaf Extract has antinociceptif and anti-inflammatory effects.

Royal Jelly is a material that has the effect of anti-lipid peroxidation. There are studies that have reported the neuroprotective effects of Royal Jelly [20].

This study showed that administration of Soursop Leaf Extract can reduce inflammation in the brains of mice, consistent with research Adewole \& Ojowole [8] but STZ-induced inflammation in mice. Royal Jelly has anti-inflammatory effects, according to research Kohno [21] which showed anti-inflammatory activity in experimental animals.

Increased levels of BDNF expected because of the effects of Royal Jelly on the synthesis of BDNF, and thus lower the apoptosis, according to research Aslan [20], which shows that Royal Jelly has antioxidant and neuroprotective effects against rabbit model treated with spinal cord injury.

In this study, a significant difference, the average number of apoptosis and cerebral edema, brain tissue taken from mice with brain injury after administration Soursop Leaf Extract and Royal Jelly. The treatment group Royal Jelly, showed a decrease edema $(72.03 \%)$, decreased apoptosis $(46.23 \%)$, a decrease in IL-1 $\beta$ $(51.5 \%)$, the increase in BDNF $(446.31 \%)$.

Compared with the control, reduction of cerebral edema and apoptosis, obtained significant group Royal Jelly dose administration of $100 \mathrm{mg} / \mathrm{kg}$ and Soursop Leaf Extract dose of $200 \mathrm{mg} / \mathrm{kg}$ (apoptosis); Royal Jelly dose of $100 \mathrm{mg} / \mathrm{kg}$, and Soursop Leaf Extract dose of $200 \mathrm{mg} / \mathrm{kg}$ and $400 \mathrm{mg} / \mathrm{kg}$ (cerebral edema). This happens because the expected anti-inflammatory and antioxidant effects of Soursop Leaf Extract [8]. While Royal Jelly has antioxidant effects and inhibit lipid peroxidation [20].

IL-1 $\beta$ is one of the few materials proinflammatory role in brain injury. IL-1 $\beta$ is secreted when there are triggers inflammatory pathways and pathway free radicals in brain injury. Decreased levels of IL- $1 \beta$ loaded significantly in the treatment group Royal Jelly dose administration of $100 \mathrm{mg} / \mathrm{kg}$ and Soursop Leaf Extract dose of $200 \mathrm{mg} / \mathrm{kg}$ and $400 \mathrm{mg} / \mathrm{kg}$. It is estimated that as a result of anti-inflammatory and antioxidant effects of Soursop Leaf Extract [8], as well as the antioxidant effects of Royal Jelly [20].

$\mathrm{BDNF}$ is a compound that has the effect of trophic (plays in the lives and development of neurons). Various kinds of stimulus will increase BDNF gene expression. Examples are light stimulation, osmotic, whisker stimulus, and physical activity increase BDNF mRNA expression in various areas in the brain [15].

Increased levels of BDNF loaded significantly in the treatment group Royal Jelly dose administration of $100 \mathrm{mg} / \mathrm{kg}$ and Soursop Leaf Extract dose of $200 \mathrm{mg} / \mathrm{kg}$. It is estimated that, when giving treatment Soursop Leaf Extract and Royal Jelly, appeared stimulus in the brain that ultimately increases brain levels of BDNF. The effect of increased BDNF in the delivery of Soursop Leaf Extract $200 \mathrm{mg} / \mathrm{kg}$ higher than the dose of $400 \mathrm{mg} / \mathrm{kg}$ body weight, may be due to the effects of toxicity [8].

To complete understanding of the relationship between the decrease in the number of cerebral edema and apoptosis with decreased levels of IL-1 $\beta$, and increased levels of BDNF, used regression analysis. From this analysis, it was found the relationship between the decrease in the number of cerebral edema and apoptosis to decreased levels of IL-1 $\beta$. There is also a correlation between the decrease in the number of cerebral edema and apoptosis to increased levels of BDNF.

\section{Conclusions}

From the results of this study concluded that administration of Soursop Leaf Extract and Royal Jelly in mice with brain injuries for 7 days:

1. Giving Soursop Leaf Extract and Royal Jelly in rats who suffered brain injuries reduce levels of IL-1 $\beta$.

2. Giving Soursop Leaf Extract and Royal Jelly in rats brain injury increases levels of BDNF.

3. Royal Jelly in rats brain injury decreases the amount of cerebral edema.

4. Soursop Leaf Extract and Royal Jelly in rats brain injury decreases the amount of apoptosis.

5. Giving Soursop Leaf Extract and Royal Jelly in rats brain injury decrease cerebral edema and apoptosis of 
neurons through increasing the ratio of BDNF / IL-1 $\beta$.

VII. Tables

Table 1. Mean body weight of experimental animals

\begin{tabular}{|c|c|c|c|c|c|}
\hline Sample & K & P1 & P2 & P3 & P4 \\
\hline 1 & 262 & 264 & 270 & 265 & 263 \\
\hline 2 & 258 & 275 & 273 & 270 & 271 \\
\hline 3 & 264 & 272 & 271 & 261 & 265 \\
\hline 4 & 260 & 262 & 259 & 258 & 269 \\
\hline 5 & 272 & 265 & 261 & 263 & 261 \\
\hline Mean & $\mathbf{2 6 3 . 2}$ & $\mathbf{2 6 7 . 6}$ & $\mathbf{2 6 6 . 8}$ & $\mathbf{2 6 3 . 4}$ & $\mathbf{2 6 5 . 8}$ \\
\hline
\end{tabular}

Table 2. Analysis of animal body weight

\begin{tabular}{|c|c|c|c|c|c|c|c|c|}
\hline & $\mathbf{N}$ & Minimum & Maximum & Mean & Std. Deviation & Variance & F & Sig. \\
\hline K & 5 & 258.0 & 272.0 & 263.200 & 5.4037 & 29.200 & .714 & .592 \\
P1 & 5 & 262.0 & 275.0 & 267.600 & 5.5946 & 31.300 & & \\
P2 & 5 & 259.0 & 273.0 & 266.800 & 6.3403 & 40.200 & & \\
\hline P3 & 5 & 258.0 & 270.0 & 263.400 & 4.5056 & 20.300 & & \\
\hline P4 & 5 & 261.0 & 271.0 & 265.800 & 4.1473 & 17.200 & & \\
\hline
\end{tabular}

Table 3. Animal treatment

\begin{tabular}{|c|c|c|c|}
\hline Group & Cerebral Contusion & Soursop Leaf Extract & Royal Jelly \\
\hline K (Control) & + & - & - \\
\hline P1 & + & $100 \mathrm{mg} / \mathrm{kg}$ & - \\
\hline P2 & + & $200 \mathrm{mg} / \mathrm{kg}$ & - \\
\hline P3 & + & $400 \mathrm{mg} / \mathrm{kg}$ & - \\
\hline P4 & + & - & $100 \mathrm{mg} / \mathrm{kg}$ \\
\hline
\end{tabular}

Table 4. Area of cerebral edema

\begin{tabular}{|c|c|}
\hline Group & Average cerebral edema (micron ${ }^{2}$ ) \\
\hline K & 5538324,04 \\
\hline P1 & 4046254,92 \\
\hline P2 & 2657322,59 \\
\hline P3 & 2958208,06 \\
\hline P4 & 1549128,31 \\
\hline
\end{tabular}

Table 5. Significance test of mean of cerebral edema

\begin{tabular}{|c|c|c|c|c|}
\hline Group & Mean & St. Dev. & F hit & Sig. \\
\hline K (control) & 5538324,0360 & 1666276,02261 & \multirow{2}{*}{$4.000^{*}$} & \multirow{2}{*}{0.015} \\
\hline P1 (soursop leaf extract 100 mg) & 4046254,9240 & 2422744,45058 & & \\
\hline P2 (soursop leaf extract 200 mg) & 2657322,5880 & 1580567,43873 & & \\
\hline P3 (soursop leaf extract 400 mg) & 2958208,0580 & 1258905,74440 & \multirow{3}{*}{} \\
\hline P4 (Royal Jelly) & 1549128,3080 & 1252735,77986 & \\
\cline { 1 - 3 } Total & $\mathbf{3 3 4 9 8 4 7 , 5 8 2 8}$ & $\mathbf{2 0 7 1 0 7 1 , 3 3 3 9 4}$ & & \\
\hline
\end{tabular}

Table 6. Apoptosis

\begin{tabular}{|c|c|c|c|c|c|}
\hline Sample & K & P1 & P2 & P3 & P4 \\
\hline 1 & 64 & 64 & 48 & 47 & 37 \\
\hline 2 & 59 & 57 & 44 & 43 & 32 \\
\hline 3 & 65 & 59 & 44 & 41 & 35 \\
\hline 4 & 68 & 54 & 45 & 46 & 34 \\
\hline 5 & 62 & 55 & 42 & 41 & 33 \\
\hline Mean & $\mathbf{6 3 , 6}$ & $\mathbf{5 7 , 8}$ & $\mathbf{4 4 , 6}$ & $\mathbf{4 3 , 6}$ & $\mathbf{3 4 , 2}$ \\
\hline
\end{tabular}

Table 7. Significance test of mean of apoptosis

\begin{tabular}{|c|c|c|c|c|}
\hline Group & Mean & St. Dev. & F hit & Sig. \\
\cline { 1 - 3 } K (control ) & 64.800 & 4.6044 & \multirow{2}{*}{$64.838^{*}$} & \multirow{2}{*}{0.000} \\
\cline { 1 - 3 } P1 (soursop leaf extract100 mg) & 58.200 & 3.7014 & & \\
P2 (soursop leaf extract200 mg) & 41.800 & 3.3466 & & \\
P3 (soursop leaf extract400 mg) & 43.200 & 3.3466 & & \\
\hline P4 (Royal Jelly) & 33.600 & 2.4083 & & \\
\cline { 1 - 3 } Total & $\mathbf{4 8 . 3 2 0}$ & $\mathbf{1 2 . 1 2 0 0}$ & & \\
\hline
\end{tabular}


Table 8. Level of IL-1 $\beta(\mathrm{pg} / \mathrm{mL})$

\begin{tabular}{|c|c|c|c|c|c|}
\hline Sample & K & P1 & P2 & P3 & P4 \\
\hline 1 & 10400 & 9200 & 8200 & 7200 & 5400 \\
\hline 2 & 10200 & 9200 & 7300 & 7200 & 4800 \\
\hline 3 & 10000 & 9900 & 7400 & 7100 & 4200 \\
\hline 4 & 10900 & 10100 & 8600 & 6800 & 5500 \\
\hline 5 & 11900 & 9900 & 6800 & 8800 & 6000 \\
\hline Mean & $\mathbf{1 0 6 8 0}$ & $\mathbf{9 6 6 0}$ & $\mathbf{7 6 6 0}$ & $\mathbf{7 4 2 0}$ & $\mathbf{5 1 8 0}$ \\
\hline
\end{tabular}

Table 9. Significance test of level of IL-1 $\beta$

\begin{tabular}{|c|c|c|c|c|c|}
\hline Group & Mean & St. Dev. & F hit & \multicolumn{2}{c|}{ Sig. } \\
\hline K (control ) & 10680.000 & 759.6052 & & \multirow{2}{*}{$47.738^{*}$} & 0.000 \\
\cline { 1 - 3 } P1 (soursop leaf extract100 mg) & 9660.000 & 427.7850 & & & \\
P2 (soursop leaf extract200 mg) & 7660.000 & 726.6361 & & & \\
\cline { 1 - 3 } P3 (soursop leaf extract400 mg) & 7420.000 & 788.6698 & & & \\
\cline { 1 - 3 } P4 (ekstrak Royal Jelly) & 5180.000 & 694.2622 & & & \\
\cline { 1 - 3 } Total & $\mathbf{8 1 2 0 . 0 0 0}$ & $\mathbf{2 0 5 0 . 6 0 9 7}$ & & & \\
\hline
\end{tabular}

Table 10. Level of BDNF (pg/mL)

\begin{tabular}{|c|c|c|c|c|c|}
\hline Sample & K & P1 & P2 & P3 & P4 \\
\hline 1 & 136 & 151 & 336 & 87 & 459 \\
\hline 2 & 52 & 78 & 383 & 194 & 511 \\
\hline 3 & 87 & 104 & 437 & 81 & 484 \\
\hline 4 & 83 & 162 & 327 & 248 & 518 \\
\hline 5 & 89 & 101 & 386 & 218 & 470 \\
\hline Mean & $\mathbf{8 9 . 4}$ & $\mathbf{1 1 9 . 2}$ & $\mathbf{3 7 3 . 8}$ & $\mathbf{1 6 5 . 6}$ & $\mathbf{4 8 8 . 4}$ \\
\hline
\end{tabular}

Table 11. Significance test of level of BDNF

\begin{tabular}{|l|c|c|c|c|}
\hline \multicolumn{1}{|c|}{ Perlakuan } & Mean & St. Dev. & F hit & Sig. \\
\hline K (control ) & 89.400 & 30.0716 & \multirow{2}{*}{$71.260^{*}$} & \multirow{2}{*}{0.000} \\
P1 (soursop leaf extract100 mg) & 119.200 & 35.7169 & & \\
P2 (soursop leaf extract200 mg) & 373.800 & 44.2911 & & \\
P3 (soursop leaf extract400 mg) & 165.600 & 76.9370 & & \\
\cline { 1 - 3 } P4 (ekstrak Royal Jelly) & 488.400 & 25.5402 & & \\
\hline Total & 247.280 & 165.0246 & & \\
\hline
\end{tabular}

Table 12. Test of Mean of Ratio BDNF/IL-1 $\beta$

\begin{tabular}{|c|c|c|c|c|}
\hline Group & Rata-rata & St. Dev. & F hit & Sig. \\
\hline K (control ) & 0.008 & 0.0029 & \multirow{2}{*}{ 72.538* } & \multirow{2}{*}{0.000} \\
P1 (soursop leaf extract100 mg) & 0.012 & 0.0036 & & \\
\cline { 1 - 2 } P2 (soursop leaf extract200 mg) & 0.049 & 0.0095 & & \\
\cline { 1 - 2 } P3 (soursop leaf extract400 mg) & 0.022 & 0.0106 & & \\
\cline { 1 - 3 } P4 (ekstrak Royal Jelly) & 0.096 & 0.0151 & & \\
\cline { 1 - 2 } Total & 0.038 & 0.0342 & & \\
\hline
\end{tabular}

Table 13. Test Results Summary Simple Linear Regression Ratio Relations BDNF / IL-1 $\beta$ with Apoptosis

\begin{tabular}{|c|c|c|c|c|c|}
\hline & Coefficients & t hitung & Sig. & F & Sig. \\
\hline Constant & 59.058 & & & 42.270 & 0.000 \\
\hline $\begin{array}{c}\text { Rasio (BDNF/IL-1 } \\
\text { beta) }\end{array}$ & -285.050 & -6.502 & 0.000 & & \\
\hline $\mathrm{R}^{2}=0.648$ & & & \\
\hline $\mathrm{F}$ table $=4.279$
\end{tabular}

Table 14. Test Results Summary Simple Linear Regression Ratio Relations BDNF / IL-1 $\beta$ with Cerebral edema

\begin{tabular}{|c|c|c|c|c|c|}
\hline & Coefficients & t hitung & Sig. & F & Sig. \\
\hline Constant & 4631741,845 & & & 10.629 & 0.003 \\
\hline Rasio (BDNF/IL-1 beta) & $-34028455,349$ & $-3,260$ & 0.003 & & \\
\hline $\mathrm{R}^{2}=0.316$ \\
\hline F table $=4.279$
\end{tabular}

\section{References}

[1]. Alejandro, A.R. Treatment of Cerebral Edema, The Neurologist, 12(2), 2006, 59-73.

[2]. Gennarelli TA, Graham DI. Neuropathology, in Silver JM, McAllister TW, Yudofsky SC (eds.) Textbook of Traumatic Brain Injury. (American Psychiatric Publishing : Washington DC, 2005) 43-44.

[3]. Clausen F, Hånell A, Israelsson C, Hedin J, Ebendal T,Mir AK,Gram H, Marklund N. Neutralization of interleukin-1 $\beta$ reduces cerebral edema and tissue loss and improves late cognitive outcome following traumatic brain injury in mice. European Journal of 
Neuroscience, 34(1), 2006, 110-123.

[4]. Bent S. Herbal medicine in the united states: review of efficacy, safety, and regulation. Journal of General Internal Medicine, 23(6), 2008, 854-9.

[5]. El-Tahir KED \& Bakeet D. The Black Seed Nigella Sativa Linn - Amine for Multicures: A Plan for Urgent Clinical Evaluation of Its Volatile Oil. J.T.U Med Sc, 2006.

[6]. Khar et al. Differential Cytotoxic Effects of Annona Squamosa seed Extract on Human Tumor Cell Lines: Role of Reactive Oxygen Species and Glutathione. Indian Academy of Sciences, 2005.

[7]. Wene K. A Flavonol Triglicoside and Investigation of The Antioxidant and Cell Stimulating Actvities Of Annona Muricata Linn. Arch Pharm Res 35, 2012.

[8]. Adewole SO \& Ojewole AO. Protective Effects of Annona Muricata Linn. (Annonaceae) Leaf Aqueous Extract on Serum Lipid Profiles and Oxidative Stress in Hepatocytes of Streptozotocin treated diabetic rats. Complementary and Alternative Medicines. African Journal Traditional, 2008.

[9]. Istiadjid MES. Analgesia dan anestesia yang umum dipakai pada hewan laboratorium. In Istiadjid MES (ed.) Buku Ajar Etik Penelitian Kesehatan (Malang: Universitas Brawijaya Press, 2011) 281-283.

[10]. Cernak, I. Animal Models of Head Trauma. The Journal of the American Society for Experimental NeuroTherapeutic 2, 2005, 410422 .

[11]. Bareyre F, Wahl F, Mcintosh TK, Stutzmann JM. Time Course of Cerebral Edema after Traumatic Brain Injury in Rats: Effects of Riluzole and Mannitol. Journal of Neurotrauma, 14(11) 2009, 839-849.

[12]. Lucas SM, Rothwell NJ, Gibson RM. The role of inflammation in CNS injury and disease. British Journal of Pharmacology, 147(S1), 2009, 232-241.

[13]. Hicks RR, Numan S, Dhillon HS, Prasad MR, Seroogy KB. Alterations in BDNF and NT-3 mRNAs in rat hippocampus after experimental brain trauma. Molecular Brain Research (48), 1997, 401-406.

[14]. Kasan U. Cedera otak patofisiologi penanganan dan biomolekuler. (Surabaya, Faculty of Medicine Airlangga University, 2006).

[15]. Binder DK, Scharfman HE. Brain-derived neurotrophic factor. Growth Factors. 22(3), 2004, 123-131.

[16]. Slemmer JE, Weber JT, DeZeeuw CI. Cell death, glial protein alterations and elevated S-100B release in cerebellar cell cultures following mechanically induced trauma. Brain research, 10(21), 2004, 159-166.

[17]. Zakirof SK. Alkaloids from Annona Muricata leaves. Chemistry of Natural Compounds, 47(2), 2011.

[18]. Miller LK. Baculovirus interaction with host apoptotic pathways. Journal of cellular physiology, 173(2), 2007, $178-82$.

[19]. De Sousa OV, Vieira GD, de Pinho JRG, Yamamoto CH \& Alves MS. Antinociceptive and Anti-Inflamatory Activities of the Ethanol Extract on Annona Muricata L. Leaves in Animal Models. International Journal of Molecular Sciences, 11. 2010, 20672078

[20]. Aslan A, Cemek M, Buyukokuroglu ME, Altunbas K, Bas O, Yusuf Yurumez. Royal jelly can diminish secondary neuronal damage after experimental spinal cord injury in rabbits. Food and Chemical Toxicology, 50, 2012, 2554-2559.

[21]. Kohno K, Okamoto I, Sano O, Arai N, Iwaki K, Ikeda M, Kurimoto M. Royal Jelly Inhibits the Production of Proinflammatory Cytokines by Activated Macrophages. Biosciences Biotechnology Biochemical, 68(1), 2004, 138-145. 